\title{
Detecção de anticorpos anti-Neospora caninum em propriedades de agricultura familiar no município de Realeza, estado do Paraná, Brasil
}

Alexandra Lays Petry', Lisangela Veiga Trevisan, Regiane Figueredo Ghisleri, Michel Fernando Fritz, Diego Kozerski, Christian

Carpeggiani Giotto, Ana Aline Kolcheski, Vitor Afonso Horn, Juliana Paula da Silva, Fagner Luiz da Costa Freitas

Laboratório de Saúde Única, Universidade Federal da Fronteira Sul (UFFS), Realeza, PR, Brasil

*Autor correspondente

e-mail: alexandralays@gmail.com

\section{Resumo}

A neosporose é uma doença causada pelo protozoário Neospora caninum, tendo como hospedeiros diversas espécies animais, incluindo caninos, equinos e animais de produção, principalmente bovinos. É considerada uma doença grave, ocasionando mortalidade neonatal, falhas reprodutivas e queda na produção de leite, sendo umas das principais causas de abortos em bovinos. A pesquisa avaliou a soroprevalência de anticorpos anti- $N$. caninum em vacas com aptidão leiteira, em fase de lactação, oriundas de 56 propriedades de agricultura familiar pertencentes ao município de Realeza/PR. 0 trabalho foi aprovado pela Comissão de Ética no Uso de Animais da Universidade Federal da Fronteira Sul, sob o protocolo 23205.004368/2016-11, sendo pesquisados 389 animais oriundos de 56 propriedades de agricultura familiar. Após a contenção do animal, realizou-se coleta de sangue pela veia coccígea, por meio de agulhas individuais e tubos com vácuo sem anticoagulante. Após a coleta, o material biológico foi encaminhado no interior de caixas de isopor com gelo ao Laboratório de Saúde Única da Universidade Federal da Fronteira Sul, Campus Realeza/PR, onde o soro foi submetido à técnica de ensaio imunoenzimático indireto (ELISA) para detecção de anticorpos IgG anti- $N$. caninum, utilizando a diluição de 1:400. A análise obteve os seguintes resultados: das 56 propriedades analisadas, $49(87,5 \%)$ apresentaram pelo menos um animal com anticorpos anti- $N$. caninum e, dentre os 382 animais examinados, 157 foram soropositivos ao parasito, representando prevalência de $41 \%$. Os resultados encontrados corroboram a importância de estudos epidemiológicos que permitam conhecer melhor o panorama da neosporose bovina no município e os principais fatores de risco que contribuem para a infecção bovina, viabilizando, consequentemente, o estabelecimento de melhores estratégias e medidas de profilaxia e controle da infecção parasitária. 